Journal of Sustainable Development of Transport and Logistics

journal home page: https://jsdtl.sciview.net

Belkacem Bouzida, I., \& Merzoug, S. (2021). Impact of logistics information systems on supply chain optimization: Case of Group Bachir Rachid. Journal of Sustainable Development of Transport and Logistics, 6(2), 60-80. doi:10.14254/jsdtl.2021.6-2.4.

\title{
Impact of logistics information systems on supply chain optimization: Case of Group Bachir Rachid
}

\author{
Ismahane Belkacem Bouzida *(D), Slimane Merzoug **(D) \\ * University of Bejaia, \\ Bejaia, 06000, Algeria \\ RMTQ, FSECSG \\ ismahane.belkacembouzida@univ-bejaia.dz \\ ** University of Bejaia, \\ Bejaia, 06000, Algeria \\ LED, FSECSG \\ slimane.merzoug@univ-bejaia.dz
}

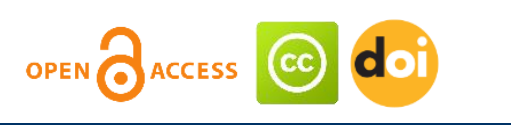

\section{Article history:}

Received: August 02, 2021

1st Revision: September 18, 2021

Accepted: November 16, 2021

\section{DOI:}

10.14254/jsdtl.2021.6-2.4

\begin{abstract}
Purpose: This paper aims to check the contribution of Logistics Information Systems - LIS to supply chain optimization in the steel industry group of Bachir Rachid. This group that owns eight independent companies and numerous points of sale and warehouses, has to be connected by such advanced systems to ensure effectiveness and profitability.
\end{abstract}

Methodology: A questionnaire was distributed among a group of employees, and the collected data was later analyzed by SPSS 25 and complemented by further structured and unstructured interviews. We have realized an analysis of variance to evaluate the impact of LIS on logistics activities, supply chain management, and integration as well as optimization. The test of Kruskal-Wallis $\mathrm{H}$ was chosen due to the non-linearity of the data.

Results: This work proves that Logistics Information Systems contribute to the performance of logistics activities, supply chain integration, and supply chain optimization through the enhancement of the efficiency of supply chain management and by the reduction of supply chain costs.

The theoretical contribution: The contribution made to the theory of logistics and supply chain management lies in confirming previous findings on the contribution of LIS to logistics and supply chain optimization in Algeria, and more specifically, in the steel industry.

Keywords: supply chain management, logistics information systems, steel industry, analysis of variance, Kruskal-Wallis $\mathrm{H}$

Corresponding author: Ismahane Belkacem Bouzida

E-mail: ismahane.belkacembouzida@univ-bejaia.dz

This open access article is distributed under a Creative Commons Attribution (CC-BY) 4.0 license. 


\section{Introduction}

Supply chain management has witnessed the introduction of diverse technics to cope with the emerging trends in the business, which are all customer-centered. Putting the customers at the core of planning to accomplish their needs requires innovative logistics solutions that depend largely on the availability of good quality information.

The emergence of new technologies has affected industries and logistics operations worldwide; they help to remove barriers on the internal and external levels of companies. Logistics information systems LIS are not only used to enhance the logistics activity of the company or the entire supply chain management, but their use also is a leverage of company performance, and its use helps minimize costs, enhance SC agility and transparency (al Naqbi, Yusoff, \& Ismail, 2018)

Although the admitted tangible and intangible benefits of these systems, yet their adoption in Algeria is slow, and it is mainly pushed by collaborations with foreign partners since companies fear the loss of possible partnerships due to the non-use of such technologies.

With the higher complexity of activities that characterizes mainly the manufacturing sector, the need to use LIS to cope with this complexity is quite important. To narrow down our research, we investigate the use of LIS in a group of steel industries in Algeria. From the above, we formulate the problem of our study as:

Does the use of logistics information systems contribute to achieving supply chain optimization?

Through this problem, we will formulate some hypotheses that will guide our research work:

$\mathrm{H}_{1}$ : Logistics Information Systems enhance supply chain management practices.

$\mathrm{H}_{2}$ : Logistics Information Systems contribute to supply chain integration.

$\mathrm{H}_{3}$ : Logistics Information Systems contribute to SC optimization.

Thus, we summarize our approach in this study the following diagram:

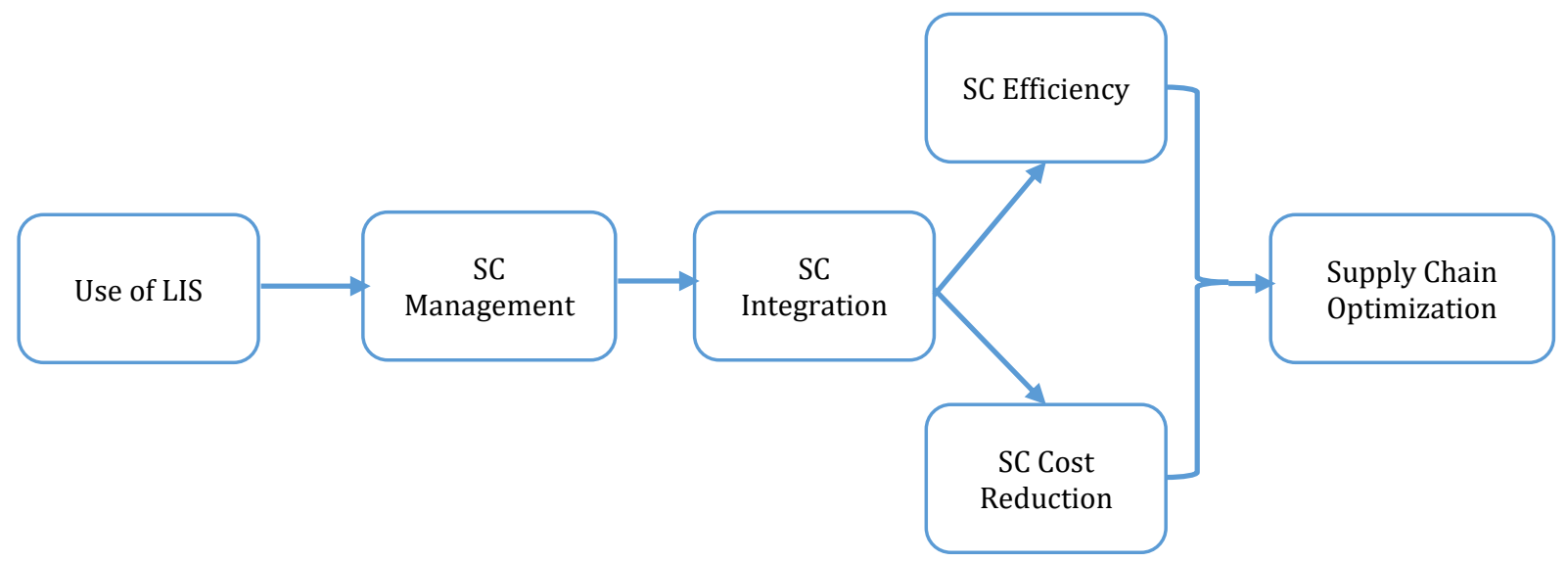

Regarding the previous studies, numerous papers evaluated the impact of LIS on company performance and particularly, logistics or supply chain management performance. To be more specific, we searched for previous studies in Algeria that included practical studies where we found that they mainly consider the ERP. Some studies weighed on the ERP with the decision-making process (Khalfi, 2018a; Nassima \& Hassane, 2020). Other studies focused on the impact of the ERP on acquiring a competitive advantage (Khalfi, 2018b) and enhancing it (Bouzoualegh \& Oudah, 2020) or evaluated the impact of this technology on organizational performance (Merouani \& Belgacem, 2020; Mokhtari, 2017). The ERP was also linked to the degree of organizational performance by (Slimani \& Boukrif, 2016). Other papers had petroleum companies as the field of their study (Hammadi, 2016; Louati, Rdjem, \& Ghattas, 2020). Another article analyzed the ERP choice and implementation process (Fellah, 2015) and the postimplementation consequences on human resources management (Berrefas, 2021).

Consequently, the importance of our study lies in the fact that no previous study in the Algerian context evaluated the implementation and the integral use of logistics information systems to enhance logistics activities and supply chain management practices up to the optimal performance of the supply chain, which are the main functions these systems were created to fulfill. 
To reach the desired results, we realized our case study by a five-point Likert questionnaire and by structured and semi-structured interviews to collect data. All the data were analyzed by SPSS 25 and Microsoft Excel 2013. We began with a descriptive analysis of the Group's logistics activities, supply chain management and integration, and the use of LIS. We further analyzed possible correlations and regression between the elements mentioned above.

This paper is organized as follows: an overview of the relevant concepts of the supply chain and the logistics information systems, then a case study in Group Bachir Rachid of Steel industry. The following provides a discussion of the found results and finally a conclusion.

\section{Review of literature}

First, we present a review of fundamental theoretical concepts of the field, which are logistics, supply chain management, and supply chain integration. We further define the Logistics Information Systems, their benefits, and the obstacle faced to reach the full performance of these technologies.

\subsection{From logistics to supply chain management}

Logistics activities have been defined as the processes that aim to create one unified plan for all the flow transfers of products and information in the company (Hesse \& Rodrigue, 2004). They help companies acquire and preserve a competitive advantage and enhance their profits in competitive markets. Good management of logistics activities is a factor of ROI increase, whether through increasing the margins or increasing the assets return (Christopher, 2016, 59).

The concept of logistics evolved with practice, and logisticians realized the need to integrate the fragmented logistics with those of customers and suppliers. Supply chain management represents the links created to coordinate the different companies upstream and downstream in the same pipeline(Christopher, 2016, 2). The main objective of relationships management upstream and downstream is to offer the final customer an added value for a minimum cost for all the chain partners.

Supply chain integration has been defined as the sharing of information throughout the supply chain by IT to accomplish on-time transactions and information transfer that contribute to decision making. Integration has three dimensions: supplier integration refers to collaboration with the company's supplier (s) to establish joint practices based on trust and information sharing. As for customer integration, it is defined as the downstream partnerships with customers who do not have to be always the end consumer, but any party that purchases the company's product like a retailer or a distributor. Finally, internal integration represents practices inside the company to share resources and information between the different departments, such as cross-functional teams (Prajogo \& Olhager, 2012).

Figure 1 below represents the stages of supply chain integration, which moves from fragmented functions in the company to functional integration in the second stage. In the third one, companies can reach internal integration, and the final stage refers to external integration with the company's partners. 
Figure 1: Supply chain integration stages
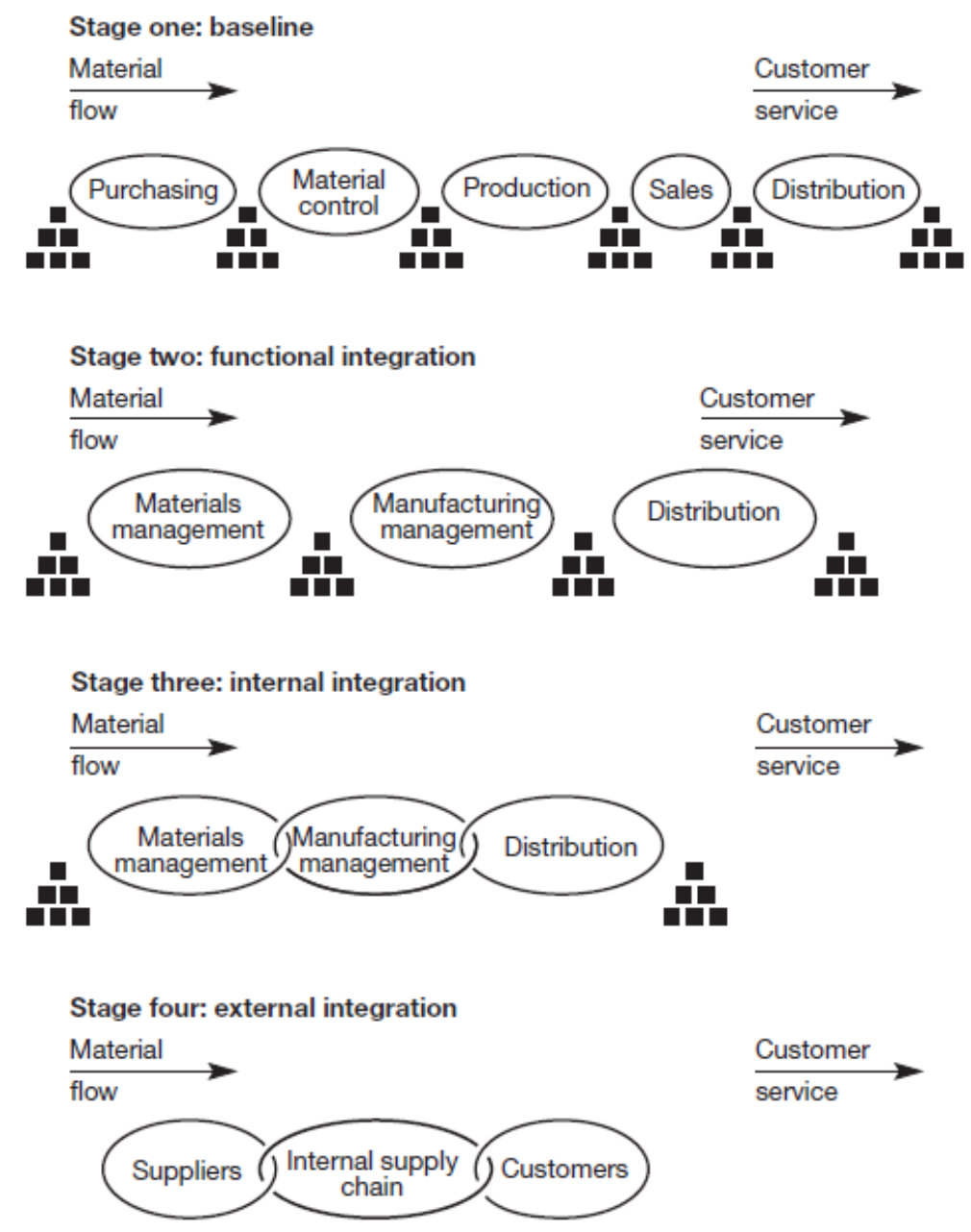

Source: Stevens, 1989

\subsection{Logistics Information Systems (LIS)}

The introduction of logistics information systems in logistics activities emerged from production planning. The complexity of this operation proved the importance of technologies to facilitate the job and reduce the time and effort needed. Even though lean management technics brought this activity to another level regarding efficiency and cost reduction like Kanban cards, waste reduction, and total quality management, nevertheless, LIS were necessary to plan material requirements and handle inventory.

Manufacturing resources management MRP was the first system deployed in the field by the early 1970 'to provide up-to-date information about the production processes and calculate the needs to be acquired by the company after analyzing the available inventory (Ptak \& Schragenheim, 2003, 4). The system was not supposed to eliminate the shortage of material but rather reduce it to a level that does not hinder production. The introduction of backward scheduling and capacity plans in MRP II further developed the system.

Just-in-time practices and the strengthening of supplier relationships, competitiveness became the object of all departments rather than production alone. The need to integrate all activities with production management was the reason for ERP to come to light. This later includes all the existing functions in the company with accurate on-time data characterized by more adequacy and exactitude. Consequently, we no longer find the implemented independently but rather as an integrated module of the ERP system with other modules, each representing company's functions like stock management, customer relations management, and transportation management.

As much as we can find these modules in the ERP package, they could also be implemented independently according to the company's needs. The use of the ERP contributes to the fast response to 
customer requirements, thus improving service levels internally and externally, drastically reducing inventory costs, and the overall logistics costs (Yusuf, Gunasekaran, \& Abthorpe, 2004). It was found that the appropriate implementation and use of the ERP are critical to the company's performance and, not only its survival in the market, but also the level of its competitiveness (Shen, Chen, \& Wang, 2016).

Supply Chain Management System- SCMS supports the business processes related to the supply chain and logistics activities by co-ordination and providing more accurate information. This system handles the logistics flow throughout the supply chain, thus reducing cycle time and logistics costs (Helo $\&$ Szekely, 2005). It would further enhance customer service and the company profitability (Hendricks, Singhal, \& Stratman, 2007)

As for the advanced planning systems - APS, they use algorithms and mathematical tools to reach optimal plans for resources utilization under the given constraints that face the company (Hvolby \& Steger-Jensen, 2010). The computerization and automatization of processes allow fast calculations of the optimal situations and the different possible alternatives that would contribute to the decisionmaking process. The APS also contributes to data accuracy, cost reduction, visibility enhancement throughout the supply chain, and reduces inventory levels leading consequently to the increase of the ROI. Other benefits might be taken out of the use of an APS, which are intangible, such as the understanding of the costs of the optimal plan and the alternative ones, remediating supply chain problems through proactive measures, and raise the level of awareness in the company (Hvolby \& Steger-Jensen, 2010).

The interpretation of the APS plans to shorter horizons can be accomplished by Supply Chain Execution System - SCE. Both systems have one alert system and work jointly on the same modules such as distribution or procurement, but SCE operates in real-time (Meyr, Wagner, \& Rohde, 2015). It detects the differences between the planned and the executed performance rapidly and is remotely linked with Transportation Management System to generate a notification for this later (Perego, Perotti, \& Mangiaracina, 2011).

Transportation management system - TMS is used for the automation of all transportation activities to come out with an optimal plan in the short term because the use of APS concerns long-term planning only. The plan could include path planning, resources allocation, and capacity utilization for the main objective to reduce operational transportation costs (Helo \& Szekely, 2005). Real on-time data enhances scheduling precision and offers more accurate information to all parties in the company, and the entire supply chain, which would help them in the decision-making process (Li \& Zhao, 2019).

Warehousing management systems are designed to track the flow of materials inside the warehouse, including the reception of these materials, storage, stock management, order picking, handling, and even transportation (Helo \& Szekely, 2005). Stock levels usually represent $50 \%$ or more of the company's assets (Christopher, 2016, 60). The total costs of maintaining a stock enclose all the following: the invested capital, the storage, and handling, obsolescence, damages and deteriorations, loss and shrinkage, insurance, and management costs (Christopher, 2016, 70). Thus, the warehousing management system provides an optimal plan for resources utilization to minimize such costs. These resources include the warehousing space, the equipment of handling and transportation, and the needed human resources.

Logistics performance is considered as an indicator of the service offered to customers compared to the used resources; in other words, it seeks customer satisfaction with minimal costs (Ouariti \& Zeroual, 2017). This justifies the need the investment in customer relationships management systems that establish customer relationships, enhance and preserve them in the long term by integrating IT infrastructure, available data, and customer knowledge to increase the amount of the value offered to customers (Heredero \& Gómez, 2014). The CRM is characterized by an easy and inexpensive implementation compared to other systems, and it helps reduce transactions costs, therefore increasing the revenue of the company and maintaining more loyal customers. Mainly, it differs from an ERP in the fact that this later is more focused on internal operations where CRM deals with the external environment.

Electronic data interchange -EDI ensures data transfer through the computerized standard systems between organizations using internal networks or external ones. It provides on-time data from transferred documents with reduced costs (Cyplik, Shvartsburg, \& Zaborowski, 2019).

Other systems complement the work of the ones mentioned above, which are the barcodes and the Radiofrequency Identification (RFID), depending on the type of the product and its margin of benefit. 
Barcodes represent an international language of coding that helps track the goods, make accurate reports about the status quo, evaluate inventory levels, and minimize errors and costs (Hong-Ying, 2009). Barcodes are cheap and easier to handle, but RFID takes less time and effort for reading and identification, yet this technology is still expensive and requires its infrastructure (chips, readers, connection to databases).

To improve the operational performance of the supply chain, it is primordial to ensure suitable suppliers and customer relationships, information sharing, and good quality of this information (al Naqbi et al., 2018; Shi, Chen, \& Ye, 2019). This means that once top management integrates the supply chain internally and externally, manages the information sharing throughout the entire network in a way that provides appropriate information for decision making, it is guaranteed to reach supply chain costs optimization and enhance its flexibility and responsiveness.

\subsection{Obstacles of LIS implementation and use}

The success of the logistics information system depends mainly on the choice of the right technology for the company, and on the availability of the appropriate infrastructure to receive these systems and cope with them. Culture and management policies implemented are also essential factors for the success of LIS (Bhandari, 2014).

Even if Algerian companies are becoming more aware of the need to implement and use LIS and the benefits expected from them, the amount of investment needed is the main obstacle. An ERP like SAP can cost around $4800 €$, added to that the maintenance cost that represents nearly $20 \%$ of the global cost (Salimov, Trutneva, \& Snegurenko, 2020). In some cases, even if the company can handle the implementation cost, the resistance to organizational change is a hampering factor, whether it comes from decision-makers or the employees.

Previous studies concluded that the main obstacle behind the reluctance of companies to implement an ERP package is the overall implementation cost and the time needed to shift from the old systems to the ERP. (Wenrich \& Ahmad, 2009) noted that the system requires a hardware and software infrastructure, databases, and networking facilities to accommodate the produced information and ensure its storage and transfer. Specialized human resources are crucial to implement, exploit the system, and train the employees.

The obstacles that prevent the company from reaching full benefits from the APS relate to the complexity of its operations, thus, inaccurate data and non-qualified employees are the main obstacles. Vendors should provide enough support for companies to adapt to their implemented APS (Hvolby \& Steger-Jensen, 2010).

The amount of raw data in the business could be challenging as well; this is notably the case of CRM since it uses information about customers, products, competition, and markets that are usually available in abundance. The issue lies in determining the best way to extract valuable data and treat it (Kumar \& Reinartz, 2018).

\section{The practice of the logistics information system in the group Bachir Rachid}

The practical part of this paper begins with a presentation of the group where we made our study, followed by the tools used for data collection and analysis. Evaluation of logistics activities, supply chain management, and supply chain integration was included in the following section, then we studied the different existing correlations and regression analysis.

\subsection{Sample presentation}

Group Bachir Rachid was founded in 1991 with the first company SPL Metal in AinYagout- Batna. The other seven companies were acquired or founded later on, and they all operate independently in the steel industry except Nouveau Pole, founded in 2009 and provides logistics and transportation services for the entire group with a fleet of 55 trucks. Three companies manufacture steel products (SARL SPL Metal- Batna, SPA Protuil- Annaba, and SARL Steelor- Oran), their raw materials are black and galvanized steel coils as well as wire rods, which are bought from the local market or imported based on the lowest prices in international markets. Thus these companies have the following 
departments: production and maintenance department that uses diverse machines for roll forming, slitting, shearing, and a wiredrawing machine. Other existing departments are sales, supply and logistics department, administration and accounting, and Hygiene and security department. Only SPA Protuil has a galvanization section and produces tiles, and it is the only company in the group that is certified ISO 2008. The other companies are commercial.

As we can observe in figure 2, the group has good coverage of the Algerian territory being present in 10 wilayas (districts) with plans to expand its network by opening other points of sale soon in Bejaia and Jijel and other production companies in Batna and Annaba. The entire network is connected by logistics information systems, thus offering real-time data to all companies of the group. Warehousing resources are shared, and the partners could even accomplish commercial transactions on behalf of one another.

Figure 2: Group Bachir Rachid's Network

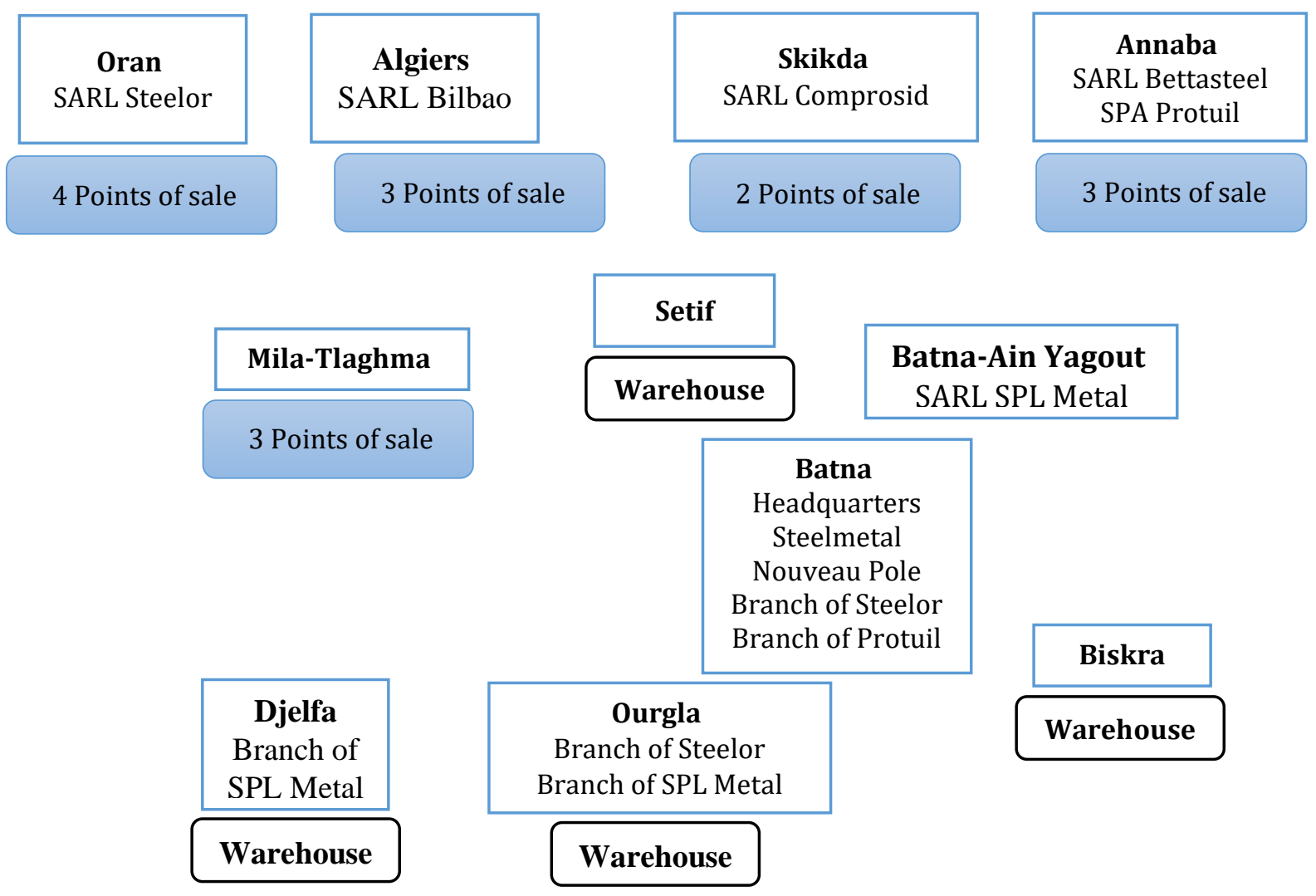

Source: Made by the researchers based on collected data

\subsection{Methodology}

A questionnaire has been prepared to identify the different Logistics Information systems used and their impact on the SC activities and optimization. It includes four sections; the first one gathers information on the different companies of our sample, the second section identifies the available LIS and the duration of use of the available ones. The following section is reserved for the diagnosis and evaluation of the group's logistics activities, supply chain management, and supply chain integration. The fourth section represents an evaluation of the available LIS, and finally, the last section measures the impact of the use of LIS on supply chain performance and optimization. The questionnaire was built on a five-point Likert scale. For confidentiality matters, no further analysis could be done, such as performance measures or modelization.

Thirty usable questionnaires were retrieved and analyzed. The respondents represent different hierarchical levels and come from all the companies of the group; as chosen by the logistics manager. After analysis, the sections of the non-available LIS have been eliminated: Supply chain management system, supply chain execution, Electronic data interchange, Barcode, Radiofrequency identification, and advanced planning system. The reliability of the questionnaire measured by Alpha Cronbach was 
found at 0.931 . Further interviews have been realized after data treatment to complement the found results and clarify ambiguities.

Firstly, we had to check with the respondents of the availability of the following logistics information systems:

1. SCMS- Supply Chain Management System

2. SCE- Supply Chain Execution System

3. ERP- Enterprise Resources Planning

4. EDI- Electronic Data Interchange

5. APS- Advanced Planning System

6. WMS- Warehouse Management System

7. TMS- Transportation Management System

8. CRM-Customer Relationship Management

9. Barcode

10. RFID- Radio Frequency Identification

The results indicate the use of the ERP, TMS, WMS, and CRM; therefore, we have excluded the other sections from the study. As we have seen before, TMS, WMS, and CRM can be used independently or as an integral part of the ERP package, which is the case of the group. The company has developed its ERP based on "Oodoo", an open-source cloud ERP. The standard online version offers only stock management, finances, and human resources management. The development of the system was suggested by the logistics manager and was realized as a collaboration between the logistics and the IT department. It has been entirely implemented in three years in all the group's companies.

\subsection{Evaluation of logistics activities and the supply chain management}

The evaluation in this section was measured by a five-point Likert Scale; the lowest stands for strongly disagree and the highest for strongly agree.

\begin{tabular}{lcccc}
\hline & 1 & 2.5 & 3.5 & 5 \\
\hline Evaluation & & Low & Medium & High \\
\hline
\end{tabular}

\subsubsection{Logistics operations}

Twelve elements have been used to evaluate the logistics activities, as shown in the table below. All the means are above 3.5, meaning the respondents strongly agree with the statements.

The steel market is not precisely volatile, and its main agents tend to agree verbally on market shares and prices. The main concern of the group Bachir Rashid is to ensure the continuity of the production for that the company proceeds to demand-forecasting (3.57), and supply planning (4.03) to meet the demand and constantly realizes market researches to track their customer's needs (3.83). The group ensures customers' orders on time (4.07) and constantly detain enough stock to meet demand (3.80). According to the logistics manager, the group keeps a significant amount of raw materials in its warehouses since this stock will not risk obsolescence or perish. However, stock turnover is constantly measured to ensure the procurement of raw materials on time, notably when they need to be imported from abroad, which generally takes six months. The lead-time takes into consideration the lead-time for importation and lead-time for production.

As for the group's network, the companies produce nearly the same steel products and use their warehouses conjointly; customers can be satisfied from any of the following locations: Batna, AinYagout-Batna, Skikda, Annaba, Algiers, and Oran with a fleet of 55 trucks. Thus, even if one company's warehouses are full, products or raw materials can be relocated to another warehouse due to their high capacity of storage, which allows the group to meet demand constantly.

Regarding material handling, the packaging and arrangement of products and raw materials are considered suitable, but the type of material handling equipment has the lowest mean among logistics activities (3.43) regarding its ability to help reduce costs. Same thing for transportation cost minimization (3.63). The general evaluation of logistics activities is 3.76 , considered high with a standard deviation of 0.930 . 
Dev.

1. The company uses demand-forecasting techniques to plan production and supply.

$3.57 \quad 1.104$

2. The company plans the purchases previously to meet demand.

$4.03 \quad 0.809$

3. The company does market research to identify customer needs.

$3.83 \quad 1.020$

4. The company delivers customer orders on time.

$4.07 \quad 0.868$

5. The company can supply the quantity requested for its customers.

$3.80 \quad 0.887$

6. The company's network allows it to deliver its products on time and requested location. $\quad 3.67 \quad 0.884$

7. The company takes into consideration the minimization of transport costs.

3.631 .189

8. The company has suitable warehouses for the storage and transfer of products and raw $4.03 \quad 0.850$ materials.

9. The company maintains sufficient stock of products and raw materials to meet demand.

$3.60 \quad 1.037$

10. The company chooses material handling equipment that minimizes costs.

11. The company uses suitable packaging for the quality of the products.

$3.43 \quad 0.971$

12. The packaging speeds up handling and storage.

Source: Made by the authors based on SPSS analysis

\subsubsection{Supply chain management}

After evaluating the group's logistics activities, we evaluate its practice of supply chain management; in other words, we check if the management handles the logistics activities as a whole or in a fragmented traditional manner. The highest mean stands for the use of information flow throughout the group's channels to plan the logistics activities (4.10). The other statements have a high evaluation as well above the mean except for building alliances and partnerships to improve the group's business (3.33). According to the logistics manager, these partnerships and collaborations have the main objective of ensuring profitability and market share by setting unified prices. Another statement with a low mean (3.03) is the minimization of stock movement during production, which might be because production is mechanical and not electronic, thus not allowing an on-time follow of stock movement as needed.

\section{Table 2: Supply chain management}

1. The company represents a significant share of sales for its suppliers.

Mea Std.

n Dev.

2. The company tries to improve the satisfaction of its end customers.

3.871 .106

3. The company considers the opinions and ideas of its suppliers regarding product quality and

3.571 .165 material flow.

4. The company processes the flow of information to plan all its activities such as purchasing,

3.670 .844 production, and distribution activities.

5. The company outsources some activities such as storage and transportation.

4.100 .995

6. The company builds alliances and partnerships with its competitors to improve its business.

7. The company can adapt to changes in demand.

8. The company regularly measures inventory turnover.

9. The company minimizes the movement of stock during production

Source: Made by the authors based on SPSS analysis

\subsubsection{Supply chain integration}

This section indicates the level of internal and external integration of the group's supply chain, beginning with the upstream integration (with suppliers), even though the company builds longterm relationships with its suppliers (3.73). However, information sharing is limited, such as stock level information (2.73), production planning, and demand forecasting (3.20). The agreements about delivery status have a mean of (3.20). Downstream integration indicates higher means compared to supplier integration, the group seems to have long-term relations with its customers (4.00) and proceeds for information sharing about market status (3.20), collects customers demand changes periodically (3.90), 
and tries to minimize response time to customer complaints (3.30). Even if the calculated mean of chain partnerships being built on mutual trust is 3.50, but the standard deviation is greater than one, which indicates that not all relationships are based on trust. Finally, the means for logistics integration and distribution activities are above the mean, but the supply chain cost reduction is only 3.07.

\section{Table 3: Evaluation of Supply chain integration}

1. The company establishes long-term partnerships with a specific group of suppliers.

2. The company builds long-term relationships with its customers.

3. Chain partnerships are based on mutual trust.

4. The company shares stock level information with its suppliers.

5. The company shares production planning and demand forecasting information with its suppliers. 3.201 .095

6. The company builds agreements regarding the frequency of delivery with its suppliers.

7. The company shares market information with its customers.

8. The company has regular contact with its customers to register changes in their requests.

9. The company minimizes the response time to customer complaints.

10. For the company, distribution includes all logistics activities ensuring the transfer of products from the company to customers.

11. Logistics activities are integrated from purchasing raw material to the delivery of products to customers.

12. The company treats the overall cost of the logistics activity comprehensively without considering each activity separately.

Mea Std.

n Dev.

3.730 .944

4.001 .017

3.501 .167

2.730 .868

3.201 .095

3.301 .022

3.900 .885

$3.30 \quad 0.988$

3.731 .048

$3.67 \quad 0.661$

3.070 .980

Source: Made by the authors based on SPSS analysis

3.440 .981

\subsection{Evaluation of the use of LIS}

In the following section, we evaluate the use of LIS by the mean and the standard deviation. Each of the logistics information systems used, the networks implemented, and the integration of LIS are analyzed as to whether they are correlated with logistics activities, with supply chain management, and with supply chain integration. To calculate correlations we used the Rho of Spearman coefficient for Likert data analysis. We have extracted only the significant correlations in the following.

\subsubsection{ERP}

All the means are above 3.50 indicating the excellent impact of the ERP in integrating the logistics activities, standardizing the flow of information, reducing time, effort, and redundancy of information, enhancing the simultaneity of activities, and the control of data entry, the access, and management of information. The system is easy to handle through an interface similar to internet networks that are also accessible to their customers, but this access is limited and only allows the customer to make orders and follow them (3.33).

\section{Table 4: Evaluation of ERP impact}

\begin{tabular}{lcc} 
& Mean & Std. Dev. \\
\hline 1. The company depends on its ERP to integrate its logistics activities. & 4.13 & 1.074 \\
2. ERP standardizes the flow of information in the company. & 4.13 & 1.074 \\
3. ERP reduces time and effort. & 4.30 & 1.088 \\
4. The ERP ensures the simultaneity of the activities of the company. & 4.30 & 1.088 \\
5. The ERP contributes to the control of data entry. & 4.50 & 0.900 \\
6. ERP makes it easier to access and manage information. & 4.43 & 1.104 \\
7. ERP eliminates information redundancy. & 4.40 \\
8. The ERP provides an interface similar to that of the Internet network. & 4.102 \\
9. The company provides access to the ERP to these suppliers and its customers. & 4.30 \\
& 3.33 & 1.398 \\
\hline
\end{tabular}

Source: Made by the authors based on SPSS analysis 


\subsection{1.a.1. Correlations between ERP and logistics activities}

The company's ability to deliver its customers' orders on time is positively correlated to the ERP's ability to reduce time and effort (.453), ensuring the simultaneity of activities (.453), controlling data entry (.592), quickly accessing and managing information (.592), eliminating information redundancy (.595), and its easily-used interface (.453). The company providing for the requested quantities by its customer is also correlated to the above elements $(.464, .464, .539, .539, .437, .464)$.

Other positive correlations exist between ERP's control of data entry (.562), managing information (.562), and eliminating redundancy (.394) with the use of the group's network to provide its products on time.

The determination of stock levels of products and raw materials to constantly meet demand is related to the ERP control of data entry (.455) and accessing information (.455). Finally, the mentioned aspects of the ERP in the table below all correlate to the appropriate choice of material handling equipment that minimizes the cost. To highlight this idea, we can give an example of the use of two forklift trucks, one can lift five tons and the other three tons, the bigger the capacity, the higher energy consumption; therefore, accessing the information on time about the nature of delivery to receive helps allocate the right forklift on time.

\subsection{1.a.2. Correlations between ERP and SC management practices}

The ERP's flow standardization helps the company to measure regularly its stock turnover (.424). This element also correlates to the ERP control of data entry (.509), its easily accessed information (.509), and its interface (.499). The company's ability to adapt to demand changes correlates to the ERP control of data entry (.432), the easy access and management of information (.432), and the easy interface (.404).

The company's efforts to increase the level of its end-customers satisfaction is similarly correlated to ERP control of data entry (.487), its easy access (.487), its elimination of information redundancy (.463), and the ERP elimination of information redundancy (.463). Minimizing stock movement during production correlates positively to the ERP interface (.413) and to offer to the company's customers and suppliers access to this interface (.372).

\subsection{1.a.3. Correlations between ERP and SC integration}

The company offering ERP access to its partners is positively correlated to sharing stock level information with its suppliers(.419) and to the minimization of response time to customer complaints (.450)0. However, it correlates negatively with regular customer contacts to note their demand changes (-.697). We also found positive correlations between sharing market information with customers and the use of the ERP to integrate logistics activities (.561), its standardization of information flow (.382), its reduction of time and effort (.444), ensuring the simultaneity of activities (.444) and its elimination of information redundancy (.424). Consequently, we conclude that the use of the ERP contributes to supplier integration and customer integration, but this later has limits due to the confidentiality policy of the group.

Distribution integration correlates positively to most aspects of ERP use (correlations between .458 and .478). The overall cost of the supply chain treatment is related to ERP integration of logistics activities (.384), the information standardization (.439), the reduction of time and effort (.417), the simultaneity of activities (.417), the elimination of information redundancy (.448), and finally to the ERP easy interface (.417).

\subsubsection{WMS}

The WMS enhances the automation of the storage activities and the identification of the perfect storage location. It enhances the accuracy of inventory information and the determination of stock levels, thus helping to reduce order times. All means are above 3.50 . 
1. The company uses WMS for the automation of storage activities.

Mean Std. Dev.

2. The company uses WMS to identify the location of appropriate storage locations.

$\begin{array}{ll}4.70 & 1.343\end{array}$

$4.83 \quad 1.117$

3. The company uses WMS to improve the accuracy of inventory information.

$4.97 \quad 0.850$

4. WMS is used to determine stock levels.

$4.50 \quad 1.480$

5. WMS helps reduce Order Time (the time from receipt of order to delivery).

$4.73 \quad 1.081$

Source: Made by the authors based on SPSS analysis

\subsection{2.a.1. Correlations between WMS and logistics}

The use of WMS to determine stock levels correlates only to procurement planning to meet demand (.459). The ability to automate storage activities by WMS correlates positively to staff training to use LIS (.420), to the contribution of LIS integration to increase the delivered value to customers (.417), and the reduction of customer service cost by LIS integration with customers and suppliers $(.444)$.

\subsection{2.a.2. Correlations between WMS and SCM}

Improving the level of customer satisfaction correlates to the use of WMS as to its ability to automate storage activities (.538), its identification of the appropriate storage locations (.509), its use to determine stock levels (.437), and to reduce order time (.432). The use of WMS to improve the accuracy of inventory information correlates to consulting SC partners regarding product quality and information flow (.469). Finally, minimizing stock movement during production correlates to WMS identifying the suitable storage locations (.374) and determining stock levels (.611).

\subsection{2.a.3. Correlations between WMS and SC integration}

Sharing stock level information with suppliers correlates to the use of WMS to determine stock levels (.532) and its use to reduce order time (.371). Sharing production plans and forecasts with suppliers correlates to automation of storage activities by WMS (.422), to the use of this system to the identification of the appropriate storage location (.426), and its use to determine stock levels (.441). The use of WMS to improve the accuracy of inventory information is correlated to periodic contacts with customers to follow up on the changes in their demands (.478). Finally, determining stock levels by WMS correlates to distribution integration (.429).

\subsubsection{TMS}

The group uses the transportation management system to plan transportation resources, contributes to organizing the transit area, and helps to track the vehicles and the products. The transportation company uses a transportation management system, GPS, Google maps application, onboard chips, and an onboard application. The transportation from the port to the warehouses is usually outsourced because the fleet can cover the group's demands.

The use of TMS ensures the tracking of the company vehicles in real-time and it provides all the technical specifications of the load, such as the name of the customer and his nature (partner or regular customer), the name of the driver, the weight of the truck, the distance, and the type of the product. The system can also ensure the automatic constant following of the state of the trucks, such as the time of the regular maintenance and their insurance documents. 
1. The company uses TMS to plan transportation resources. Dev.

2. The TMS contributes to the organization of the transit area and the docks.

3. TMS improves transport activity by tracking vehicles and goods.

$4.07 \quad 1.552$

$4.13 \quad 1.408$

$4.50 \quad 1.225$

$4.23 \quad 1.395$

Source: Made by the authors based on SPSS analysis

\subsection{3.a.1. Correlations between TMS and logistics activities}

Transportation resources planning by TMS correlates to purchases planning to meet demand (.475), to delivering customers' orders on time (.444), and to the choice of the suitable packaging to the quality of the products (.413). Purchases planning also correlates to organizing the shipment area by TMS (.638) and delivering customer orders on time correlates to the improvement of transport by TMS through tracking (.414). Finally, tracking vehicles and goods by TMS has a positive correlation with the suitable packaging of products (.486).

\subsection{3.a.2. Correlations between TMS and SCM}

Planning transportation resources by TMS correlates positively with the company's efforts to enhance customer satisfaction (.368). As for the minimization of stock movement during production, it correlates to planning transportation resources by TMS (.676) to the TMS contribution to the organization of transit area (.420) and the improvement of transport by tracking vehicles and goods (.488).

\subsection{3.a.3. Correlations between TMS and SC Integration}

The use of TMS by the group correlates positively to the following aspects of supply chain integration: The use of TMS to plan transportation resources correlates to production planning and demand forecasting sharing with suppliers (.390), to the minimization of the response time to customer demand (.411), and distribution integration (.647). At the same time, the use of TMS in the organization of transit areas correlates to the first and third elements. Finally, tracking vehicles and goods by TMS correlates to distribution integration.

\subsubsection{CRM}

CRM helps attract new customers and preserve their contacts; it is used to request real-time information on their customers and facilitate the flow of information. It also provides automatic suggestions to improve customer service and measures the effectiveness of the marketing strategy. All the above contribute to enhancing the level of service offered to the group's customers with all the means above 3.05 .

\section{Table 7: Evaluation of CRM impact}

Mean Std.

Dev.

1. CRM is used to attract and retain new customers.

2. The CRM is used to control the points of contact with the customers.

$4.00 \quad 1.462$

3. The business uses CRM to request real-time customer information.

$4.00 \quad 1.365$

4. The business uses CRM to facilitate and accelerate the flow of information.

$3.93 \quad 1.337$

4. The business uses CRM to facilitate and accelerate the flow of information.

$4.10 \quad 1.322$

5. The company uses CRM to have automatic suggestions regarding customer service.

$3.97 \quad 1.245$

6. The company uses CRM to measure the effectiveness of marketing activity and the rate of sales. $4.13 \quad 1.224$

7. The business uses CRM to make good decisions for its customers.

$3.93 \quad 1.311$

Source: Made by the authors based on SPSS analysis 


\subsection{4.a.1. Correlations between CRM and logistics activities}

Using CRM to attract and retain new customers correlates to purchase planning (.365), while its use to control the points of contact with customers is linked to demand forecasting to plan production (.394) and to purchases planning (.393).

\subsection{4.a.2. Correlations between CRM and SCM}

The use of CRM to facilitate and accelerate the flow of information correlates positively to the minimization of stock movement during production (.423).

\subsection{4.a.3. Correlations between CRM and SC integration}

Sharing stock level information with the supplier correlates with the use of CRM to make better decisions for customers (.400). Similarly, sharing production planning and demand forecasts correlate to the use of CRM to attract new customers and retain them (.468) as well as to use it to control the points of contact with customers (.537). Sharing market information with the company's customers correlates positively to finding and retaining new customers by CRM (.405) and the ability of the system to facilitate and accelerate the flow of information (.424). Distribution integration is linked to making new customers by CRM (.381), controlling their contact points (.388), and facilitating the flow of information by CRM (.508). Finally, the company minimizing the response time to customer complaints correlates to all aspects of CRM, with correlations ranging from .423 to 631 .

\subsubsection{Networks}

According to the obtained responses regarding the use of the networks, the group depends on the internet network and emails for information transactions. Internet is also used in purchasing and distribution activities while social media helps to identify suppliers and customers and recognize their needs while an intranet is also used in internal activities and extranet in external transactions. The lowest mean stands for the company offering its employees smartphones used in transactions (2.95) since such devices and their use are offered to a limited number of employees.

Table 8: Evaluation of the use of networks

\begin{tabular}{|c|c|c|}
\hline & Mean & $\begin{array}{l}\text { Std. } \\
\text { Dev. }\end{array}$ \\
\hline 1. The business depends on the Internet to exchange information & 4.53 & 1.106 \\
\hline 2. The company uses email for the exchange of information among its employees. & 4.53 & 0.900 \\
\hline $\begin{array}{l}\text { 3. The company uses the Internet in its activities, such as purchasing, production, and } \\
\text { distribution. }\end{array}$ & 4.17 & 1.147 \\
\hline 4. The company uses social media to learn about the needs of its suppliers and customers. & 3.87 & 1.042 \\
\hline 5. The company offers its employees smartphones to perform internal and external transactions. & 3.03 & 1.650 \\
\hline 6. The company uses the extranet to communicate with its suppliers, customers, and partners. & 3.90 & 0.885 \\
\hline \multirow[t]{2}{*}{ 7. The company uses the intranet in its internal activities. } & 4.10 & 0.845 \\
\hline & 4.02 & 1.082 \\
\hline
\end{tabular}

Source: Made by the authors based on SPSS analysis

\subsection{5.a.1. Correlations between the use of networks and logistics activities}

Purchases planning correlates to the use of the internet to exchange information (.411) and to the use of the internet in different logistics activities such as purchasing or distribution (.367). This later correlates also to the company providing the requested quantities by customers (.631), to the company's networks (.534), and the choice of the suitable material handling (.729). The exchange of information by the internet and by emails among the employees correlates to the choice of material handling (.500, .413). Moreover, the use of smartphones by employees to perform internal and external transactions is linked to the choice of suitable packaging of products (.377), and the acceleration of product handling 
by the appropriate packaging (.519); this later is also correlated to the use of extranet to communicate with suppliers, customers, and partners (.430).

\subsection{5.a.2. Correlations between the use of networks and SCM}

The use of networks by the group is correlated to the following aspects of supply chain management, firstly, the use of extranet with suppliers, customers, and partners is correlated to the significant share that the company represents from its supplier's sales (.557), as for the internet, it is correlated with the company's effort to enhance its customers' satisfaction (.554). Offering smartphones to employees to accomplish internal and external transactions is linked to information flow processing to plan logistics activities (.406).

The use of social media for market awareness correlates to building alliances and partnerships with competitors to improve the business (.398), which correlates similarly to the use of intranet in internal activities (.617).

The company's ability to adapt to demand changes correlates to the use of the internet to exchange information (.503), to the use of emails to exchange information among employees (.466), and to the use of the internet in purchasing, production, or distribution (.750). Those are linked as well to the measuring of the company turnover regularly $(.635, .577, .767)$, however, the minimization of stock movement during production is only correlated to the exchange of information by the internet (.489) and by emails among employees (.363).

\subsection{5.a.3. Correlations between the use of networks and SC integration}

Consulting suppliers regarding their product quality and material flow correlate to exchanging information by internet (.438) and by emails among employees (.380). Sharing market information with customers correlates to the use of the internet in different logistics activities (.529) as for distribution integration; it correlates to using the internet to exchange information (.433), to transfer the information by employees through emails (.408), and to use the internet in logistics activities (.444). The integration of logistics activities is linked to the use of smartphones to accomplish internal and external transactions (.549). Finally, the integral handling of logistics costs by the company correlate to exchanging information by the internet (.363), by emails (.369), and using the internet in logistics activities (.364).

\subsubsection{Integration of LIS logistics information systems}

Evaluation of LIS integration and their impact on logistics activities and supply chain management is not an easy task; the means in this section vary around 3.50 but are not so high. The employees consider the use of LIS as an encouraging factor to enhance the level of service of the supply chain by increasing the added-value offered to their customers, developing new products or services, standardizing the processes between supply chain partners, establishing collaborative approaches between them, and enhance the joint decision-making initiatives.

LIS integration upstream and downstream helps reduce different logistics costs as in supply, storage, production, distribution, and customer service. It also reduces the lead-time, enhances reactivity to customer demand, and increases the overall profit of the supply chain.

To achieve such integration, the company trains its staff to use LIS and invests resources for developing and updating its systems and their integration. Nevertheless, the standard deviation for staff training is high (1.000) since the employees find it insufficient for their everyday practice. 


\begin{tabular}{llrc} 
Table 9: Evaluation of the LIS integration & & \\
& & $\begin{array}{c}\text { Mea } \\
\text { n }\end{array}$ & $\begin{array}{c}\text { Std. } \\
\text { Dev. }\end{array}$ \\
\hline Resources & 1. The company trains its staff to use LIS. & 3.50 & 1.000 \\
Deployme & 2. The company invests resources in the development, updating of LIS and their & 3.50 & 0.827 \\
nt & integration. & 3.45 & 0.999 \\
\hline SC & 3. LIS integration contributes to increasing the delivered value to customers. & 3.50 & 0.761 \\
Efficiency & 4. LIS integration helps develop new products or services. & 3.50 & 0.688 \\
& 5. LIS integration allows processes standardization between supply chain partners. & 3.35 & 0.813 \\
& 6. LIS integration facilitates the establishment of collaborative approaches with & & \\
& suppliers/customers. & 3.40 & 0.681 \\
& 7. LIS integration improves the process of joint decision-making with & 3.60 & 0.754 \\
& suppliers/customers. & 3.75 & 0.716 \\
& 8. LIS integration allows adaptation to situations of uncertainty. & 3.55 & 0.759 \\
& 9. LIS integration with suppliers/customers allows reducing lead times. & & \\
& 10. LIS integration with suppliers/customers allows responding better to customer & 3.80 & 0.768 \\
\hline & demands. & 3.45 & 0.759 \\
& 11. LIS integration with suppliers/customers allows ensuring better profits. & 3.45 & 0.759 \\
\hline SC Cost & 12. LIS integration with suppliers/customers allows reducing supply costs. & 3.50 & 0.688 \\
Reduction & 13. LIS integration with suppliers/customers allows reducing storage costs. & 3.45 & 0.759 \\
& 14. LIS integration with suppliers/customers allows reducing production costs. & 3.50 & 0.889 \\
& 15. LIS integration with suppliers/customers allows reducing distribution costs. & & \\
\hline & 16. LIS integration with suppliers/customers allows reducing customer service \\
& costs. & 3.52 & 0.789
\end{tabular}

Source: Made by the authors based on SPSS analysis

\subsection{6.a.1. Correlations between LIS integration and logistics activities}

Using demand-forecasting techniques to plan production and supply correlates to the resources invested by the company in developing, updating LIS, and integrating them (.475). As for delivering the right quantities to meet customer demand, this correlates to training employees to use LIS (.394), to resources invested in LIS development and integration (.442), and to LIS integration contributing to increase the value offered to customers (.400). The spread of the company's network is also correlated to the past elements $(.418, .661, .498)$ and to LIS integration that allows reducing the lead-time $(.396)$, respond better to customers' demands (.537), and to ensuring better profits (.400).

Taking into consideration the minimization of transport costs correlates to the contribution of LIS integration to ensure better profits (.379) while keeping enough stock to meet customer demand at any time is correlated to LIS integration increasing the delivered value (.564) and to LIS integration reducing customer service costs (.402). On another hand, the right choice of material handling equipment that minimizes costs correlates to staff training to use LIS (.383), resources invested in LIS (.516), and LIS integration contributing to high values offered to customers (.560). Finally, the choice of appropriate packaging that accelerates the handling and storage correlates positively to these elements of LIS integration: helping develop new products and services (.528), allowing the company to adapt to situations of uncertainty (.366), reducing the lead-time (.398), and ensuring better profits (.502).

\subsection{6.a.2. Correlations between LIS integration and SCM}

The resources invested by the company in LIS development and integration are correlated to the efforts made by the company to enhance the satisfaction of its customers (.463), to its ability to adapt to demand changes (.369), and to the regular measurement of inventory turnover (.436). LIS integration contributing to offering more value to customers is linked to the company's ability to adapt to changes (.454) and the regular measurement of inventory turnover (.507). Furthermore, LIS integration helping to create new products or services is correlated to the significant share that the company represents of its supplier's sales (.634), to information flow processing for logistics planning (.514), and outsourcing activities (.586) while the contribution of LIS integration to reducing lead times is only correlated to information flow processing to plan (.488). In addition to that, LIS integration allowing the company to 
better respond to customer demands is positively linked to regular inventory turnover measuring (.364), and LIS integration allowing to ensure better profits is correlated to logistics planning through information flow processing (.534).

\subsection{6.a.3. Correlations between LIS integration and SC integration}

Building chain partnerships upon mutual trust correlates positively to the contribution of LIS integration to reducing lead times (.364) and allowing processes standardization between SC partners (.414). Sharing production planning and demand forecasting correlates solely to the resources invested by the company in LIS development and integration (.376). As for building agreements regarding deliveries with suppliers, it is correlated with many aspects of LIS integration, starting with staff training to use LIS (.545), LIS contribution to increasing value for customers (.615), LIS integration allowing process standardization (.629), facilitating the establishment of collaborative approaches with SC partners (.464), and improving joint decision making with suppliers and customers (.442). This correlates also to allow the reduction of the costs of storage (.547), production (.464), distribution (.547), and customer service (.689).

Establishing regular contact with customers to note changes in their demand correlates to LIS integration contributing to creating new products and services (.546), allowing to reduce lead times (.419) and to ensure better profits (.393). In contrast, distribution integration correlates to staff training to use LIS (.469) and LIS helping create value that is more significant for customers (.395). Other positive correlations exist between the integration of logistics activities and LIS integration contributing to adapting to uncertainty (.372) and to reducing lead times (.384). At last, we have found other positive correlations between the overall treatment of logistics costs and staff training to use LIS (.447), LIS integration allowing process standardization (.433), better responding to customer demand (.480), and improving joint decision making with SC partners (.501), as well as costs reduction in storage (.394), distribution (.394), and customer service (.412).

\section{Impact of LIS on Supply Chain Optimization}

To analyze the impact of LIS in Group Bachir Rachid, we checked first the distribution of the data using the Kolmogorov-Smirnov test: a non-parametric test since our data is ordinal. The results of $\mathrm{P}$ are not all higher than 0.05; thus the normality of the data is not obtained. For this reason, we performed the Kruskal-Wallis $\mathrm{H}$ test to analyze the variance of the parameters on the grouping variables. This test is significant at $\mathrm{P}<0.05$ (referring to the exact significance in the tables below). Two elements have been excluded from SC optimization, which relates to resources deployed to use and integrate LIS due to their insignificance to the model.

As we see in table 10, the Kruskal-Wallis $\mathrm{H}$ test is significant for TMS $(\mathrm{P}=0.017)$ and CRM $(\mathrm{P}=$ 0.001). This indicates that these two systems have a significant impact on logistics activities.

\begin{tabular}{|c|c|c|c|c|c|}
\hline & ERP & WMS & TMS & Networks & CRM \\
\hline Kruskal-Wallis- H & 2,356 & 3,050 & 7,062 & 2,603 & 10,773 \\
\hline df & 2 & 2 & 2 & 2 & 2 \\
\hline Asymp. Sig. & 0,308 & 0,218 & 0,029 & 0,272 & 0,005 \\
\hline Exact Sig. & 0,338 & 0,237 & 0,017 & 0,292 & 0,001 \\
\hline Point Probability & 0,000 & 0,002 & 0,000 & 0,001 & 0,000 \\
\hline
\end{tabular}

\footnotetext{
a. Kruskal Wallis Test

b. Grouping Variable : Logistics

Source: Made by the authors based on SPSS analysis
}

The impact of LIS on SC management is to be found significant only for CRM P=0.0019. This indicates the importance of dealing with customers' relations through CRM to make decisions regarding supply chain management. 


\begin{tabular}{lccccc} 
Table 11: Impact of LIS of SC Management & & & & \\
& ERP & WMS & TMS & Networks & CRM \\
\hline Kruskal-Wallis- H & 0,333 & 1,060 & 3,161 & 1,580 & 7,167 \\
df & 2 & 2 & 2 & 2 & 2 \\
Asymp. Sig. & 0,847 & 0,588 & 0,206 & 0,454 & 0,028 \\
Exact Sig. & 0,856 & 0,598 & 0,212 & 0,474 & 0,019 \\
Point Probability & 0,001 & 0,001 & 0,000 & 0,000 & 0,000 \\
\hline
\end{tabular}

a. Kruskal Wallis Test

b. Grouping Variable : Supply Chain Management

Source: Made by the authors based on SPSS analysis

Based on the results of the Kruskal-Wallis $\mathrm{H}$ test and considering all the significant correlations found between the use of LIS and logistics activities as well as supply chain management, we can accept $\mathbf{H}_{\mathbf{1}}$ : Logistics Information Systems enhance supply chain management practices.

SC integration is influenced by the use of ERP $(\mathrm{P}=0.043)$, WMS $(\mathrm{P}=0.036)$, and the use of networks $(\mathrm{P}=0.049)$. For Group Bachir Rachid, achieving higher levels of SC integration depends on the use of these systems.

\begin{tabular}{lccccc} 
Table 12: Impact of LIS on SC integration & & & & \\
& ERP & WMS & TMS & Networks & CRM \\
\hline Kruskal-Wallis- H & 5,605 & 5,789 & 4,638 & 5,461 & 3,821 \\
df & 2 & 2 & 2 & 2 & 2 \\
Asymp. Sig. & 0,061 & 0,055 & 0,098 & 0,065 & 0,148 \\
Exact Sig. & 0,043 & 0,036 & 0,085 & 0,049 & 0,154 \\
Point Probability & 0,000 & 0,000 & 0,000 & 0,000 & 0,000 \\
\hline
\end{tabular}

Kruskal Wallis Test

b. Grouping Variable : SC Integration

Source: Made by the authors based on SPSS analysis

The means related to the use of LIS by the group were mostly higher than the average, added to that the positive correlations that were obtained between the use of the different LIS and the internal integration of the supply chain as well as external integration with customers and suppliers. Therefore, we accept $\mathbf{H}_{2}$ : Logistics Information Systems contribute to supply chain integration.

To study the impact of LIS on the elements of SC optimization, we consider the two following factors, SC Efficiency and SC Cost Reduction. For supply chain efficiency, the results of the Kruskal-Wallis $\mathrm{H}$ test are significant only for the use of networks $(\mathrm{P}=0.001)$. This means that the Group depends on the use of networks to ensure joint decision-making with SC partners, establish collaborative approaches, adapt to situations of uncertainty, reduce lead times and better respond to customer demands. Networks also contribute to creating new products and services, increasing the added value to customers, and ensuring better profits.

\begin{tabular}{lccccc} 
Table 13: Impact of LIS of SC Efficiency & ERP & WMS & TMS & Networks & CRM \\
\hline Kruskal-Wallis- H & 0,063 & 0,139 & 0,513 & 10,009 & 0,117 \\
df & 1 & 1 & 1 & 1 & 1 \\
Asymp. Sig. & 0,802 & 0,709 & 0,474 & 0,002 & 0,732 \\
Exact Sig. & 0,812 & 0,720 & 0,486 & 0,001 & 0,746 \\
Point Probability & 0,015 & 0,018 & 0,013 & 0,000 & 0,018 \\
\hline
\end{tabular}

a. Kruskal Wallis Test

b. Grouping Variable : SC Efficiency

Source: Made by the authors based on SPSS analysis

LIS appear to be better used to reduce supply chain costs in Group Bachir Rachid. The test results are all significant except for CRM. The use of the ERP $(\mathrm{P}=0.048)$, WMS $(\mathrm{P}=0.004)$, TMS $(\mathrm{P}=0.030)$, and the networks $(\mathrm{P}=0.001)$ contribute to reducing supply, storage, production, distribution, and customer service costs. 


\begin{tabular}{lccccc} 
Table 14: Impact of LIS of SC Cost Reduction & & & & \\
& ERP & WMS & TMS & Networks & CRM \\
\hline Kruskal-Wallis- H & 7,187 & 10,643 & 7,907 & 13,309 & 3,930 \\
df & 3 & 3 & 3 & 3 & 3 \\
Asymp. Sig. & 0,066 & 0,014 & 0,048 & 0,004 & 0,269 \\
Exact Sig & 0,048 & 0,004 & 0,030 & 0,001 & 0,287 \\
Point Probability & 0,000 & 0,000 & 0,000 & 0,000 & 0,000 \\
\hline
\end{tabular}

a. Kruskal Wallis Test

b. Grouping Variable: Cost Reduction

Source: Made by the authors based on SPSS analysis

The implementation and use of LIS and their integration with supply chain partners were found to contribute to enhancing supply chain efficiency and reducing the different logistics costs (supply, storage, production, and distribution). We accept then as well $\mathbf{H}_{3}$ : Logistics Information Systems contribute to SC optimization.

\section{Conclusion}

LIS are technological tools that enhance the efficiency and effectiveness of logistics operations and supply chain management. The choice of the right technology is crucial to ensure value creation and optimize supply chain management practices. Group Bachir Rachid is appropriately using LIS, yet they have not made the most benefit out of these systems. Many improvements could be performed by the top management to use these systems more efficiently and consequently, enhance supply chain management and integration where we have not found optimal results. The Group could start by offering company staff training to better use LIS. It should also consider building more trust-based alliances and partnerships with its suppliers and customers that would allow them to share more information, therefore, ensuring more transparency and enhancing the use of LIS. Another procedure to be discussed is the offering of more sophisticated devices such as smartphones to accomplish internal and external transactions to the employees.

Even if steel transformation is a lean production in a very stable market, but new trends must be implemented to ensure future competitiveness and profitability. Lean management focuses on the reduction, and possibly, the total elimination of waste to ensure optimal use of resources. In such a case, the company must maximize economies of scale and seek efficiency in resources utilization through a generally predictable demand.

The company should also consider the transfer from mechanical production to digital production that can be easily integrated into LIS, facilitates process standardization, and enhances the accuracy of information. It also helps to reduce costs, increases the personalization of products, and reduces stock levels, energy consumption, and materials waste (Christopher, 2016, 267).

\section{Funding}

The authors received no direct funding for this research.

\section{Conflicts of interest/Competing interests}

We declare no conflict of interest

\section{Availability of data and material}

Not applicable

\section{Acknowledgements}

We also wish to thank Mr. Fateh Telli from Group Bachir Rashid for his valuable contribution to this paper. 


\section{Citation information}

Belkacem Bouzida, I., \& Merzoug, S. (2021). Impact of logistics information systems on supply chain optimization: Case of Group Bachir Rachid. Journal of Sustainable Development of Transport and Logistics, 6(2), 60-80. doi:10.14254/jsdtl.2021.6-2.4.

\section{References}

al Naqbi, R. A. K., Yusoff, R. B. M., \& Ismail, F. B. (2018). Supply Chain integration and Sustainable supply chain performance: A case of Manufacturing firms from UAE. International Journal of Engineering \& Technology, 7(4.7), 424-429.

Berrefas, I. (2021). Implantation des Progiciels de Gestion Intégrés (ERP) et Pratiques de la Gestion des Ressources Humaines au sein des Entreprises Algériennes Cas de l'entreprise de télécommunications «Algérie Télécom». Revue Finance \& marchés, 8(2), 34-46.

Bhandari, R. (2014). Impact of technology on logistics and supply chain management. IOSR journal of business and management, 2, 17.

Bouzoualegh, R., \& Oudah, F. (2020). مساهمة نظام تخطيط موارد المؤسسة في تعزيز الميزة التنافسية للمؤسسة دراسة الإسة

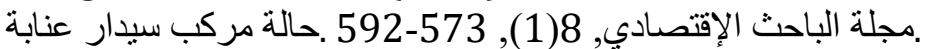

Christopher, M. (2016). Logistics \& supply chain management: Pearson UK.

Cyplik, P., Shvartsburg, L., \& Zaborowski, T. (2019). EDI system in logistic management of an enterprise. LogForum 15 (2), 205-221.

Fellah, K. (2015). Méthodologie de sélection et de mise en place d'un Progiciel ERP au sein d'une entreprise : cas de SAIIDAL Algérie. 8(1), 40-71.

Hammadi, N. (2016). Implantation du Système ERP dans les entreprises du secteur pétrolier en Algérie. Cas : Benchmarking entre ENAFOR, ENTP et Schlumberger Algérie. Revue finance et marchés, 3(2), $1-20$.

Helo, P., \& Szekely, B. (2005). Logistics information systems: an analysis of software solutions for supply chain co-ordination. Industrial Management \& Data Systems, 105(1), 5-18.

Hendricks, K. B., Singhal, V. R., \& Stratman, J. K. (2007). The impact of enterprise systems on corporate performance: A study of ERP, SCM, and CRM system implementations. Journal of operations management, 25(1), 65-82.

Heredero, C. P., \& Gómez, C. G. (2014). The contribution of CRMs to the ability of market segmentation: the case of the VIPs group. Procedia Technology, 16, 355-364.

Hesse, M., \& Rodrigue, J.-P. (2004). The transport geography of logistics and freight distribution. Journal of transport geography, 12(3), 171-184.

Hong-Ying, S. (2009). The application of barcode technology in logistics and warehouse management. Paper presented at the 2009 First International Workshop on Education Technology and Computer Science.

Hvolby, H.-H., \& Steger-Jensen, K. (2010). Technical and industrial issues of Advanced Planning and Scheduling (APS) systems. Computers in Industry, 61(9), 845-851.

Khalfi, I. (2018a). Information systems and decision-making effectiveness-Case study ofN'gaous Company for Preserves.

Khalfi, I. (2018b). استخدام تكنولوجيا المعلومات في الأنشطة اللوجيستية و أثرها في تحقيق ميزة تنافسية للمؤسسة. Université de Batna 1-Hadj Lakhder.

Kumar, V., \& Reinartz, W. (2018). Customer Relationship Management Concept, Strategy, and Tools Springer Texts in Business and Economics(Third Edition).

Li, L., \& Zhao, L. (2019). Design about Cost Management of Logistics Enterprises under the Background of the Big Data and Informatization. Paper presented at the 2018 International Symposium on Social Science and Management Innovation (SSMI 2018).

Louati, K., Rdjem, K., \& Ghattas, M. S. (2020). Analysis the use of the ERP system in the Algerian

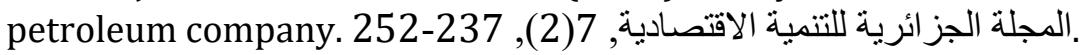

Merouani, R., \& Belgacem, S. (2020). The impact of ERP information quality on performance creativity: Study a sample of companies operating in the regions of Setif and Bordj Bou Arreridj. مجلة العلوم الاقتصادية و التسيير و العلوم التجارية, 13(1), 480-496. 
Meyr, H., Wagner, M., \& Rohde, J. (2015). Structure of advanced planning systems Supply chain management and advanced planning (pp. 99-106): Springer.

Mokhtari, H. A. H. (2017). L'impact Des Systèmes Erp «Enterprise Ressource Planning» Sur La Performance Organisationnelle De L'entreprise : Etude à Partir Des Entreprises En Algérie. Revue d'ECONOMIE et de MANAGEMENT, 16(1).

Nassima, O., \& Hassane, O. (2020). The effect of enterprise resource planning 'ERP'on management control and decision-making process. Les Cahiers du Mecas, 16(2), 107-118.

Ouariti, O. Z., \& Zeroual, P. L. (2017). L'impact Des Systèmes D'information Sur La Performance Des Chaines Logistiques: Une Revue De Littérature. European Scientific Journal, 13(4).

Perego, A., , S., \& Mangiaracina, R. (2011). ICT for logistics and freight transportation: a literature review and research agenda. International Journal of Physical Distribution \& Logistics Management.

Prajogo, D., \& Olhager, J. (2012). Supply chain integration and performance: The effects of long-term relationships, information technology, and sharing, and logistics integration. International Journal of Production Economics, 135(1), 514-522.

Ptak, C. A., \& Schragenheim, E. (2003). ERP: tools, techniques, and applications for integrating the supply chain: Crc Press.

Salimov, R., Trutneva, A., \& Snegurenko, A. (2020). ERP System as a Method of Effective Economic Management by the Example of the Russian Federation. Paper presented at the International Scientific Conference" Far East Con"(ISCFEC 2020).

Shen, Y.-C., Chen, P.-S., \& Wang, C.-H. (2016). A study of enterprise resource planning (ERP) system performance measurement using the quantitative balanced scorecard approach. Computers in Industry, 75, 127-139.

Shi, Y. W., Chen, P.-K., \& Ye, Y. (2019). Factors for improving and moderating a successful supply chain. Journal of Business Economics and Management, 20(1), 20-42.

Slimani, R., \& Boukrif, M. (2016). Les changements organisationnels et managériaux induits par l'implantation d'un ERP: cas de l'entreprise ALCOST Bejaia. مجلة الإقتصاد و المجتمع, 112(12), 12 . 12 .

Wenrich, K., \& Ahmad, N. (2009). Lessons learned during a decade of ERP experience: A case study. International Journal of Enterprise Information Systems (IJEIS), 5(1), 55-73.

Yusuf, Y., Gunasekaran, A., \& Abthorpe, M. S. (2004). Enterprise information systems project implementation:: A case study of ERP in Rolls-Royce. International Journal of Production Economics, 87(3), 251-266.

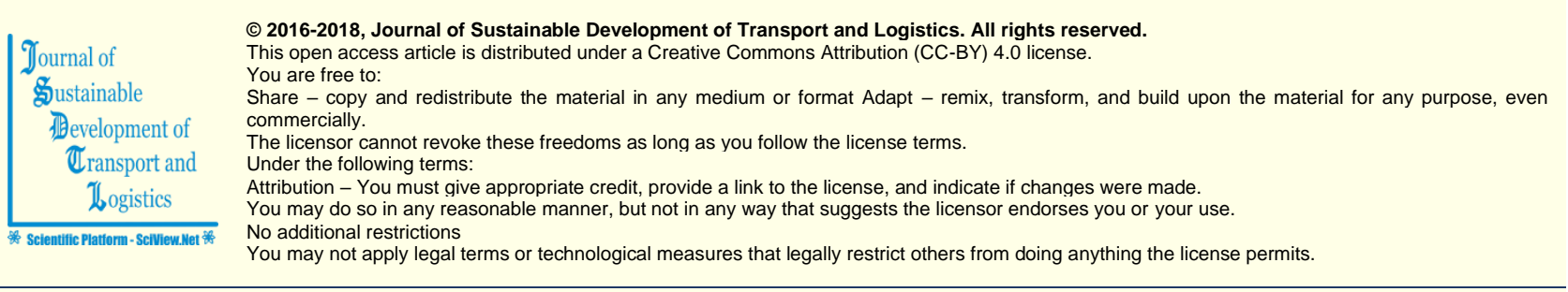

Journal of Sustainable Development of Transport and Logistics (ISSN: 2520-2979) is published by Scientific Publishing House "CSR", Poland, EU and Scientific Publishing House "SciView", Poland, EU

Publishing with JSDTL ensures:

- Immediate, universal access to your article on publication

- High visibility and discoverability via the JSDTL website

- Rapid publication

- Guaranteed legacy preservation of your article

- Discounts and waivers for authors in developing regions

Submit your manuscript to a JSDTL at https://jsdtl.sciview.net/ or submit.jsdt|@sciview.net 